\title{
SIMPLE AND RAPID METHOD FOR THE SIMULTANEOUS ANALYSIS OF TAMOXIFEN, ENDOXIFEN, AND 4-HYDROXYTAMOXIFEN IN DRIED BLOOD SPOT USING LIQUID CHROMATOGRAPHY-TANDEM MASS SPECTROMETRY
}

\author{
BAITHA PALANGGATAN MAGGADANI ${ }^{1}$, YAHDIANA HARAHAP ${ }^{*}$, HARMITA $^{1}$, SAMUEL J. HARYONO ${ }^{2}$, TESANIKA \\ RIBKA JOULIN SITORUS ${ }^{1}$
}

1Faculty of Pharmacy, Universitas Indonesia, Depok, Indonesia, ${ }^{2}$ Surgical Oncology Division, MRCCC Siloam Hospital, Jakarta, Indonesia Email: yahdiana03@yahoo.com

Received: 21 Nov 2019, Revised and Accepted: 01 Apr 2020

\section{ABSTRACT}

Objective: Tamoxifen (TAM) is a hormonal therapy that is clinically proven to reduce breast cancer recurrence by blocking estrogen receptor, mainly through its active metabolites, 4-hydroxytamoxifen (4HT) and endoxifen (END), which have a higher affinity to ER than TAM itself. The objective of the present study was to develop and validate simple and rapid LC-MS/MS method for analysis TAM and its metabolites simultaneously in dried blood spot (DBS) sample for monitoring studies purposes.

Methods: Optimization was done by evaluating several parameters that affect the efficiency of DBS preparation, such as blood spot volume, drying time and extraction method from the DBS paper. The effectiveness of chromatographic conditions was also optimized by varying flow rate, mobile phase combination and gradient. Clomiphene was used as the internal standard.

Results: The result showed that preparation of $20 \mu \mathrm{l}$ blood spot volume with 120 min of drying time and 25 min of extraction time using 1 ml methanol was the most efficient condition and also fulfilled recovery and matrix effect requirement according to FDA and EMA guidelines. The separation was performed on UPLC Class $\mathrm{BEH} \mathrm{C}_{18}$ using formic acid $0.1 \%$-formic acid $0.1 \%$ in acetonitrile (35:65) as the mobile phase in isocratic mode at $0.25 \mathrm{ml} / \mathrm{min}$ with a total analysis time of $4 \mathrm{~min}$

Conclusion: This method has successfully fulfilled all validation requirements referring to EMA and FDA guidelines.

Keywords: Tamoxifen, Endoxifen, 4-hydroxytamoxifen, Chlomiphene, Dried blood spot, Optimization

(C) 2020 The Authors. Published by Innovare Academic Sciences Pvt Ltd. This is an open access article under the CC BY license (http://creativecommons.org/licenses/by/4.0/) DOI: http://dx.doi.org/10.22159/ijap.2020v12i3.36434. Journal homepage: https://innovareacademics.in/journals/index.php/ijap

\section{INTRODUCTION}

Tamoxifen (TAM) is a hormonal therapy that is given to premenopausal patients with estrogen receptor-positive type of breast cancer. TAM treatment for $5 \mathrm{y}$ after surgery has been proven to reduce the recurrence rate of ER+breast cancer by $50 \%$ in treatment five years after surgery and reduce the $30 \%$ mortality rate $[1,2]$. TAM is a prodrug that go through metabolism in hepatic mediated by cytochrome P450 enzyme via N-demethylation followed by 4hydroxylation. Demethylation product of tamoxifen via CYP3A4, namely $\mathrm{N}$-desmetyltamoxifen (NDT) is the most abundant metabolite but not active to estrogen receptors. NDT then metabolized to 4hydroxy-N-desmethyltamoxifen or Endoxifen (END) mediated by CYP2D6. There are also other metabolic pathways through hydroxylation of tamoxifen to 4-hydroxytamoxifen (4HT). This pathway is mediated not only by CYP2D6 but also by CYP3A4 and CYP2C19. However, this pathway is classified as minor [3].

TAM is clinically proven to reduce breast cancer recurrence by antagonist action of its active metabolite, END, and 4HT to the estrogen receptor. Those two metabolites have a higher affinity to the estrogen receptor than TAM itself [4]. END shows more potent antiestrogenic activity, about 100 fold more potent than TAM. Compared to 4HT, END shows higher plasma concentrations than 4HT, thus make END become a surrogate endpoint for tamoxifen therapeutical monitoring. Two large retrospective studies, conducted by Madlensky and Saladores have shown a correlation between END level and disease-free survival in patients with early breast cancer treated with tamoxifen have shown a positive relationship between the availability of END in the blood and disease-free survival rates in early breast cancer patients treated with tamoxifen $[5,6]$. Madlensky declared $5.97 \mathrm{ng} / \mathrm{ml}$ as the threshold, while Saladores stated the level of $15 \mathrm{nmol} / \mathrm{l}$ was the threshold at which patients with levels below that had worse results compared to those with higher levels. However, these END levels showed high variability between patients, widely based on CYP2D6 genetic polymorphism status [7, 8]. The need for an effective and efficient bioanalytical method that also provides fast and reliable sample preparation is essential to determine TAM and its active metabolites, in order to do TAM therapeutical drug monitoring.

Several previous studies have published the analysis method of TAM and its metabolites in serum and plasma biosamples using the HPLC and also LC-MS/MS. [9-12]. Recently, Dried Blood Spot (DBS) has become a prominent alternative bio sampling for therapeutic drug monitoring. Different from the conventional venipuncture method: the DBS method collected the blood from a finger prick. This procedure is less invasive than venipuncture, thus more convenient and straightforward with better patient comfort. DBS also guarantees higher stability of the analyte and is easier to transport from the sampling site to the test laboratory [13]. However, the concern that arises from DBS is the small volume of blood samples, which results in fewer levels than in plasma and serum. Therefore, a more sensitive analysis technique is required. In this study, we focused on developing a simple and also sensitive method for TAM, END, and 4HT analysis using LC-MS/MS system with clomiphene (CLO) as an internal standard. Optimization was done by evaluating several parameters that affect the efficiency of DBS preparation, such as blood spot volume, drying time, and extraction method from the DBS paper. The effectiveness of chromatographic conditions was also optimized by varying flow rate, mobile phase combination, and gradient.

\section{MATERIALS AND METHODS}

\section{Methods}

Reference standard samples and materials

END E/Z mixture and 4HT were bought from Santa Cruz Biotechnology (USA), while TAM was obtained from Sigma-Aldrich (Singapore). Clomiphene (CLO) as the internal standard was purchased from Fabbrica Italiana Sintetici (Italy). Chemical reagent 
and solvent to be used in this research, such as acetonitrile HPLC grade, Formic acid, and methanol were obtained from Merck (Germany). DBS card used in this research was Perkin Elmer 226 paper obtained from PerkinElmer (USA), and whole blood for validation was obtained from the Indonesian Red Cross.

\section{Instrumentation}

Chromatography system was using the UPLC C-18 BEH Acquity column with dimension $2.1 \times 100 \mathrm{~mm}$ and particle size of $1.7 \mu \mathrm{m}$.
Column temperature was set at $30^{\circ} \mathrm{C}$. LC-MS/MS system was using Waters Xevo Triple Quadrupole. The MS system is controlled by MassLynx Software Waters (Milford, USA). Multiple reaction monitoring (MRM) chromatograms in the positive ion electrospray ionization mode were used in this system. Mass transitions of $\mathrm{m} / \mathrm{z}$ were optimized for TAM, END, 4HT and CLO by infusion of the respective analytes in methanol. MS settings for capillary voltage, desolvation gas, cone voltage and collision refers to a previous study [14], the data are shown in table 1.

Table 1: ESI MS/MS operating parameter

\begin{tabular}{|c|c|c|c|c|c|c|}
\hline Analyte & Fragment $(\mathrm{m} / \mathrm{z})$ & Capillary (kV) & Desolvatio & & Cone (V) & Collision (V) \\
\hline & & & $\operatorname{Temp}\left({ }^{\circ} \mathrm{C}\right)$ & Rate (L/h) & & \\
\hline TAM & $372.2>72.27$ & 3.50 & 350 & 650 & 50 & 27 \\
\hline END & $374.29>58.2$ & & & & 45 & 30 \\
\hline $4 \mathrm{HT}$ & $388.29>72.19$ & & & & 50 & 27 \\
\hline CLO & $402>100.17$ & & & & 45 & 25 \\
\hline
\end{tabular}

\section{Calibration standard and quality control (QC) sample}

Quality control (QC) solution and calibration sample were prepared from a separate stock solution. The preparation of the stock solution and working solution of analytes and internal standard followed the previous method with modification $[14,15]$. Stock solutions were prepared by diluting analyte in methanol $(1,000 \mathrm{ng} / \mathrm{ml})$. Intermediate solution was made by diluting the stock solution $(100$ $\mathrm{ng} / \mathrm{ml}$ ). This intermediate solution was diluted to obtain a working solution. Calibration samples must be freshly prepared for every run in whole blood by diluting working solutions with whole blood blank. Clomiphene (CLO), Internal standard stock solution was prepared in methanol $(1000 \mathrm{ng} / \mathrm{ml})$.

\section{Optimization of chromatographic condition}

Mobile phase was optimized using four combinations of formic acid, methanol and acetonitrile (table 2).

The elution system was optimized in gradient and isocratic elution. Flow rate was also optimized to obtain efficient analysis time in the range of $0.1-0.3 \mathrm{ml} / \mathrm{min}$. System suitability test was conducted using optimum analysis condition.

Table 2: Combination of mobile phase

\begin{tabular}{ll}
\hline A & B \\
\hline Formic Acid $0.1 \%$ & Formic acid $0.1 \%$ in methanol \\
Formic Acid $0.2 \%$ & Formic acid $0.2 \%$ in acetonitrile \\
Formic Acid $0.1 \%$ & Acetonitrile \\
Formic Acid $0.1 \%$ & Formic acid $0.1 \%$ in acetonitrile \\
\hline
\end{tabular}

\section{Optimization of sample pretreatment and extraction process}

The pretreatment and extraction sample process refer to Antunes, et al., with optimization at several stages. Optimizations carried out at the pretreatment stage include the volume of blood collection, drying time and sonication time. Blood from the finger prick was collected in a microtube and pipetted with a micropipette to obtain a quantitative sample volume. The blood volume was varied 10,20 and $30 \mu \mathrm{l}$. The optimum volume was then spotted on DBS paper and dried. Drying time was varied at $30 \mathrm{~min}, 1 \mathrm{~h}$, and $2 \mathrm{~h}$. Tests were carried out at (Lower Limit of Quantification) LLOQ and Upper Limit of Quantification (ULOQ) concentrations. Observations were made by comparing retention times and areas of the three variations. The spotting volume which gives the best results is continued at the validation stage

Optimization at the extraction stage was carried out at sonication time, which varied in 25,30 , and $45 \mathrm{~min}$. $100 \mu \mathrm{l}$ whole blood containing $0.1 \%$ clomiphene and $1000 \mu \mathrm{l}$ methanol as an extraction solvent was added to the cut DBS in a tube. $850 \mu \mathrm{l}$ of the sample mixture was dried under nitrogen with a temperature of $55^{\circ} \mathrm{C}$ for 15 min, and the dried extract was then dissolved in the mobile phase. The sample mixture in the mobile phase was centrifuged for $10 \mathrm{~min}$ at $3000 \mathrm{rpm}$. The supernatant was poured to an autosampler vial. 10 $\mu \mathrm{l}$ of the sample was injected onto the LC-MS/MS system [14,15]

\section{Validation assay}

Full validation assay was performed according to the Food and Drug Administration (FDA) (2018) and the European Medicines Agency (EMA) (2011) guidelines for bioanalytical method validation [16, 17].

\section{Selectivity}

The selectivity test is carried out to test the ability of the bioanalysis method to distinguish analytes and internal standards from endogenous components in the matrix. The selectivity test used whole blank blood from six different sources, each analyzed and compared for interference. The existence of confounding components can still be accepted if the response obtained does not exceed $20 \%$ of the LLOQ in the analyte and does not exceed $5 \%$ of the internal standard.

\section{Linearity}

Calibration curves were made by plotting the peak area ratio (PAR) against the standard calibration concentration in a whole blood stimulation. PAR is a comparison between analytes responses compared with IS responses. Calibration level for TAM ranged between $5-200 \mathrm{ng} / \mathrm{ml}$; END $1-40 \mathrm{ng} / \mathrm{ml}$, and 4-HT 0.5-20 $\mathrm{ng} / \mathrm{ml}$. The acceptance criteria for each concentration on average must not exceed $\pm 15 \%$ deviation from the nominal value and $\pm 20 \%$ for LLOQ.

\section{Accuracy and precision}

Within run and between run assay for determining accuracy and precision was carried out from 5 replicates of quality control solution in LLOQ, QCL, QCM and QCH level. The \% CV and \%diff for each concentration must not exceed $15 \%$, except LLOQ is not exceed $20 \%$

\section{Recovery}

This test aims to determine the extraction efficiency of the TAM, END and 4-HT and IS from the DBS sample. Recovery test was performed by comparing the response of analytes extracted from three replicates of QCL, QCM and QCH samples, with a neat standard solution. Recovery of the analyte need not be $100 \%$, but must be consistent, precise, and reproducible ( $15 \%$ for the $\% \mathrm{CV}$ value). 


\section{Carry-over}

Samples in the blank, LLOQ, and ULOQ concentrations containing TAM, END, and 4HT were extracted and injected to the LC-MS/MS system by following these steps: LLOQ, ULOQ, and blank. The acceptance criteria established for the carry-over is a maximum of $20 \%$ for the $\%$ carry-over.

\section{Dilution integrity}

Standard solutions of TAM, END, and 4HT were diluted in whole blood to obtain the concentration above the ULOQ concentration, precisely at twice the QCH concentration. Furthermore, the solution was reconstituted until half of the concentration and a quarter of the concentration is obtained. The assay was performed with five replicates for each concentration. Dilution shall not affect accuracy and precision if the \%diff and \%CV value are not above $15 \%$.

\section{Stability}

\section{a. Standard solution stability}

Standard solutions of TAM, END, 4HT, and CLO with a concentration of $1000 \mu \mathrm{g} / \mathrm{ml}$ was injected one by one into the LC-MS/MS system as described above. The short term stability tests were carried out at 0,6 , and $24 \mathrm{~h}$ after storing the standard solutions at room temperature. The long term stability tests were carried out at 0 and $20 \mathrm{~d}$ after storing the standard solutions in the freezer $\left(-20^{\circ} \mathrm{C}\right)$. The assays were performed with two replicates. The acceptance criteria established for the stock solution stability is a maximum of $10 \%$ for the $\%$ diff value.

\section{b. Short term stability in DBS}

Standard solutions of TAM, END, and 4HT were diluted in whole blood to obtain QCL and QCH concentration, then extracted and injected into the LC-MS/MS system. The short term stability tests in DBS were carried out at 0,6 , and $24 \mathrm{~h}$ after storing the standard solutions at room temperature before being analyzed. The assays were performed with three replicates. The acceptance criteria established for the short term stability in DBS is a maximum of $15 \%$ for the \%diff and \%CV value.

\section{c. Long term stability in DBS}

Standard solutions of TAM, END, and 4HT were diluted in whole blood to obtain QCL and QCH concentration, then extracted and injected into the LC-MS/MS system. The long term stability tests in DBS were carried out at 0 and $20 \mathrm{~d}$ after storing the standard solutions in the refrigerator $\left(4^{\circ} \mathrm{C}\right)$ before being analyzed. The assays were performed with three replicates. The acceptance criteria established for the short term stability in DBS is a maximum of $15 \%$ for the \%diff and $\% \mathrm{CV}$ value.

\section{d. Autosampler stability}

Standard solutions of TAM, END, and 4HT were diluted in whole blood to obtain QCL and QCH concentration, then extracted and injected into the LC-MS/MS system. The analysis was carried out at 0 and $24 \mathrm{~h}$ after storing the sample in the autosampler before being analyzed. The assays were performed with three replicates. The acceptance criteria established for the short term stability in DBS is a maximum of $15 \%$ for the $\%$ diff and $\% \mathrm{CV}$ value.

\section{RESULTS AND DISCUSSION \\ Optimization of sample volume}

The sample volume was optimized in the range of 10-30 $\mu$ l to obtain the lowest volume for patient convenience. Blood then spotted in Perkin Elmer 226 and dried at room temperature. Sample was prepared then analyzed with the optimum chromatographic condition. The results showed that more sample volume could increase the analyte area, but no effect showed in retention time. 20 $\mu \mathrm{l}$ was chosen as the optimum volume considering patient convenience. 50 and $60 \mu \mathrm{l}$ as reported in the previous study, was too much to obtain from a finger prick and eventually painful for the patient. $20 \mu \mathrm{l}$ sample spot showed an adequate area of chromatograms as $30 \mu \mathrm{l}$ spot and also proven to give adequate recovery and LLOQ. This study shows that the application of this method will be more convenient for patients, compared to the study of Antunes et al. (2014) which required $60 \mu \mathrm{l}$ and Tré-Hardy et al. (2016) which required $50 \mu \mathrm{l}$ for the sample volume $[15,18]$ (fig. 1).

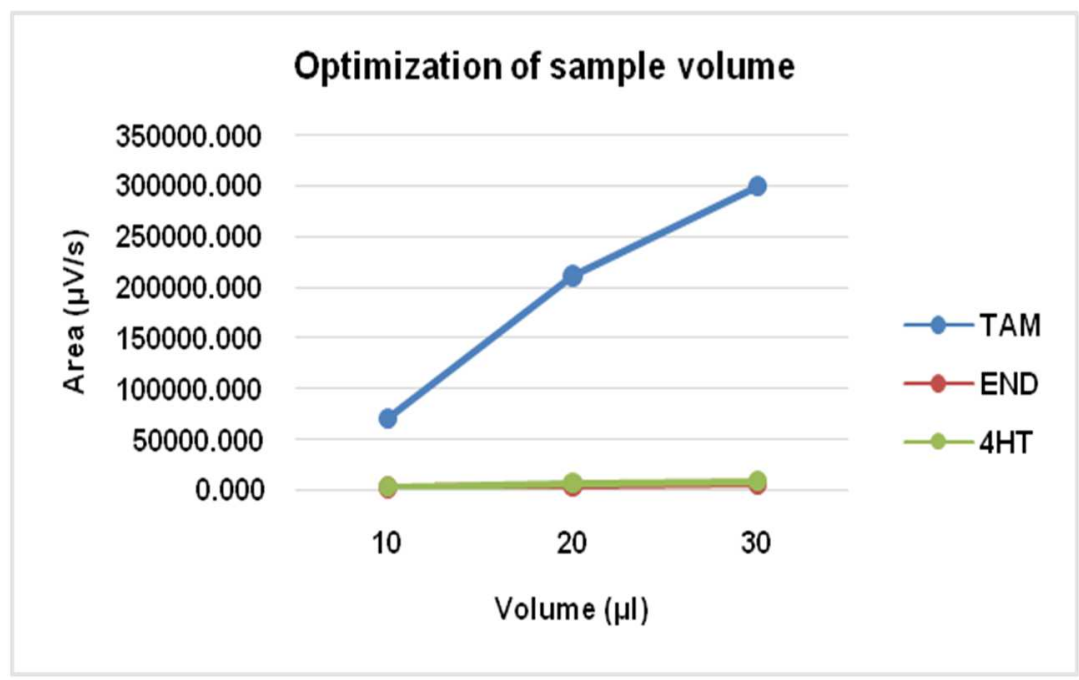

Fig. 1: Optimization sample spot volume of DBS and its influence to area chromatograms of TAM, END and 4HT

\section{Optimization of drying time}

Drying time was optimized in the range of $30 \mathrm{~min}$ to $2 \mathrm{~h}$. The sample was dried at $25^{\circ} \mathrm{C}$ for $30 \mathrm{~min}, 1 \mathrm{~h}$, and $2 \mathrm{~h}$. The results showed that $30 \mathrm{~min}$ and $1 \mathrm{~h}$ were too short for drying the sample because of those resulted in small analyte area and unstable chromatograms. Meanwhile, dry the sample for $2 \mathrm{~h}$ resulted in a more stable chromatogram than the others. This concluded that $2 \mathrm{~h}$ is the most suitable drying time for this study. Optimization of blood sample drying time has also been done previously by Koster et al. in 2015.[19] The drying time of the DBS sample affects the area of chromatograms and recovery. In this study, drying time up to $2 \mathrm{~h}$ was adequate to give a functional area of chromatograms. We did not conduct a longer drying time since $2 \mathrm{~h}$ was already fulfilled all validation parameter criteria and also due to analysis efficiency. Based on the results of these studies, it can be concluded that the drying time of blood samples can affect the area produced and affect recovery parameters in the study (fig. 2). 


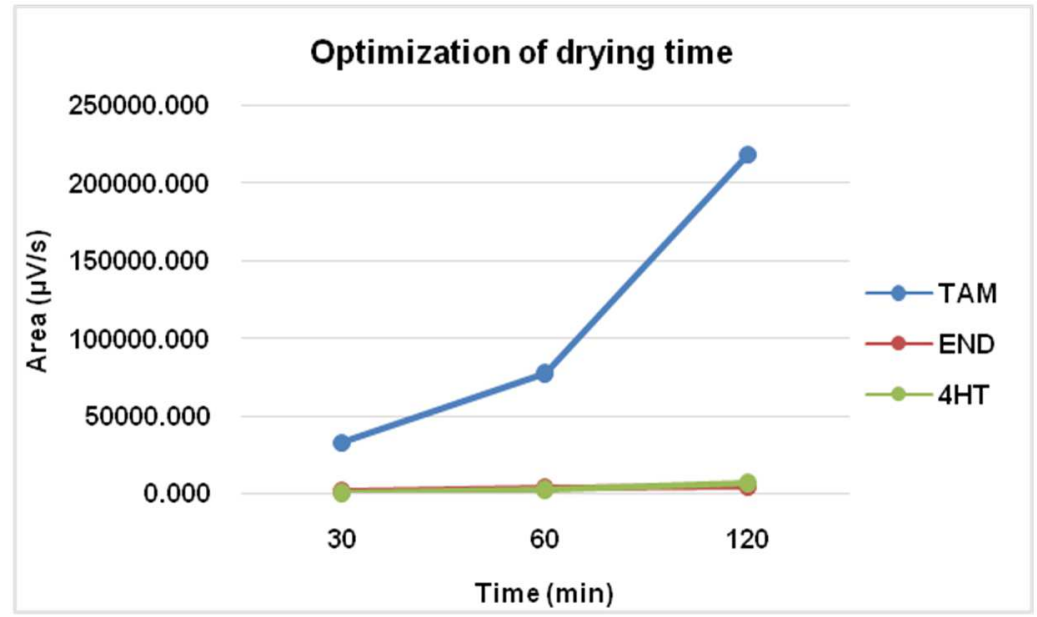

Fig. 2: Optimization of drying time of DBS and its influence to area chromatograms of TAM, END and 4HT

\section{Optimization of extraction solvent volume}

The volume of the extraction solvent was optimized in the range of 500-1000 $\mu \mathrm{l}$. Based on the test results obtained, an increase in the volume of the extracting solution causes an increase in the area of the analyte. The test results showed that there is a significant difference in the area of the analyte produced. The volume of 1000 $\mu \mathrm{l}$ showed the highest area that indicates a good recovery (fig. 3).

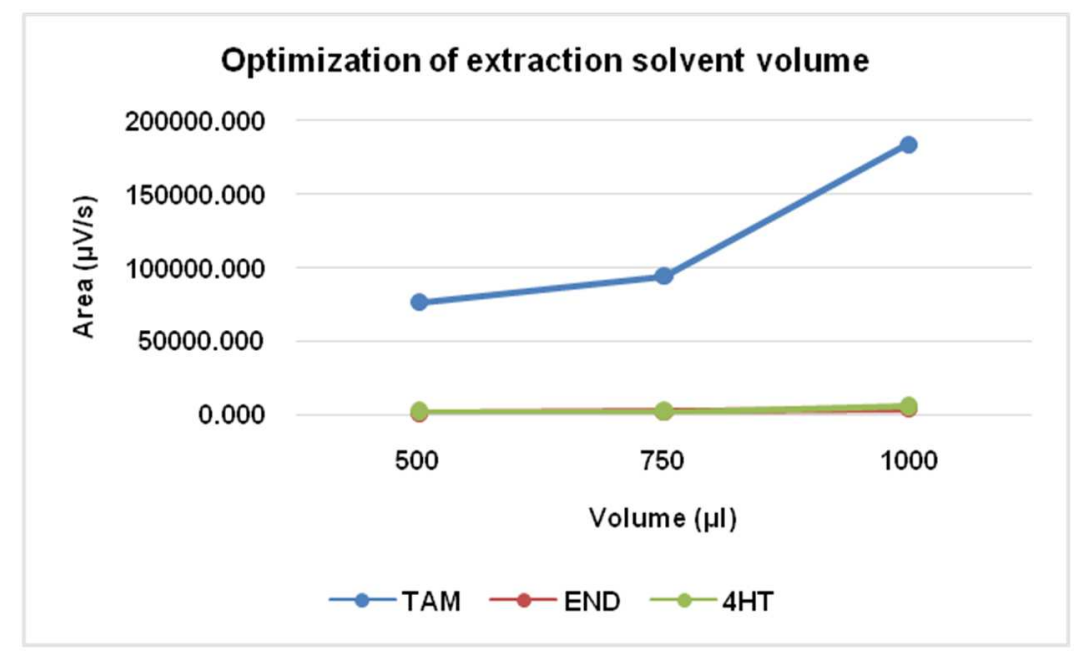

Fig. 3: Optimization of extraction solvent volume and its influence to area chromatograms of TAM, END and 4HT

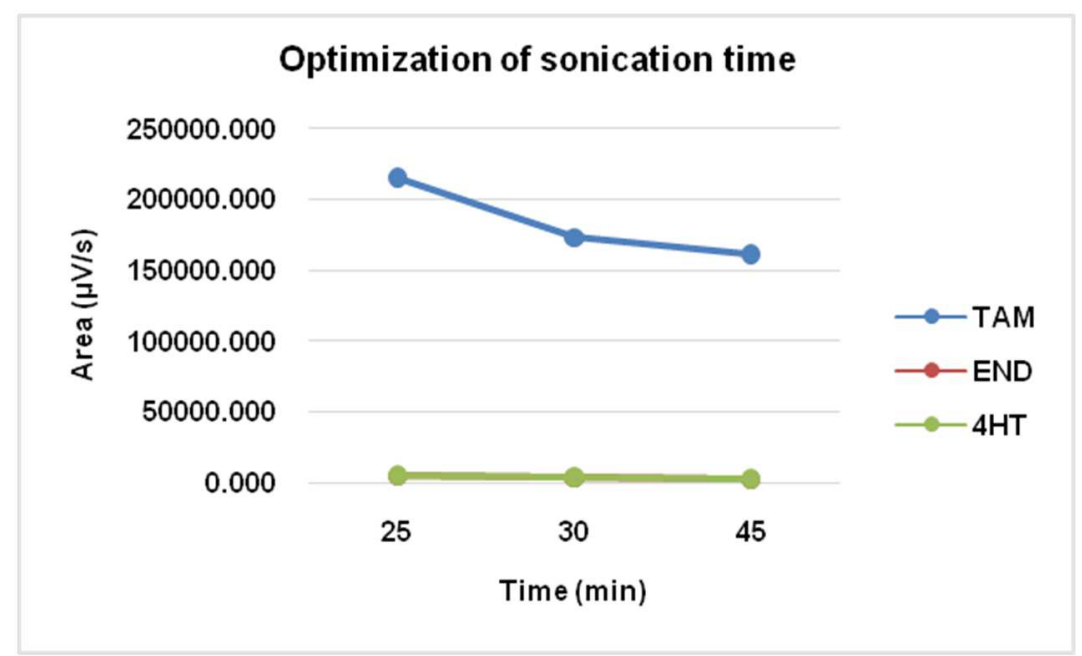

Fig. 4: Optimization of sonication time and its influence to area chromatograms of TAM, END and 4HT 


\section{Optimization of sonication time}

The sonication time was optimized in the range of 25-45 min to obtain a good chromatogram in a possibly shortest time. The results indicated an increase in the duration of sonication time could cause a decrease in area, and the chromatogram was not well separated. 25 min was chosen as the optimum sonication time because it gave the highest analyte area in the shortest time (fig. 4).

\section{Optimization of sample analysis}

Based on the results obtained, the retention time generated from the four mobile phase combinations has no significant difference. The combination of $0.1 \%$ formic acid with $0.1 \%$ formic acid in acetonitrile (35:65) was chosen as the most optimum combination of the mobile phase because it produced a better area of analyte and

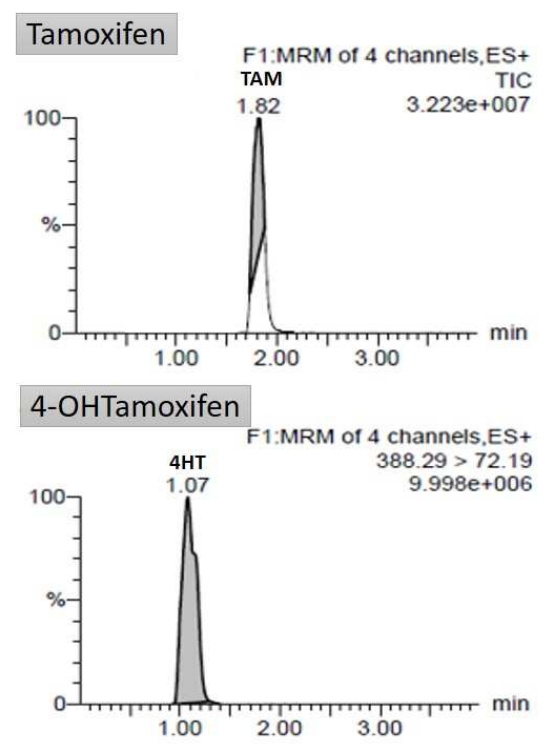

internal standard with a better chromatogram than other mobile phase combinations. When compared with the results of the elution using the gradient elution method, the shape of the chromatogram produced in the analysis with the isocratic method is better, where the peak of the four components can be adequately separated, and the resulting peak shape does not experience tailings and fronting as shown in fig. 5 . In addition, the retention time produced in the analysis with the isocratic method at 35:65 composition was also faster than that of gradient elution. Therefore, the isocratic method with a composition of 35:65 was chosen as the elution method in this analysis. When compared with other previous studies using the gradient elution method, this elution method is simpler because the mobile phase composition does not change during the analysis process, and the analysis time is shorter (fig. 5). The result of system suitability tests was summarized in table 3 .
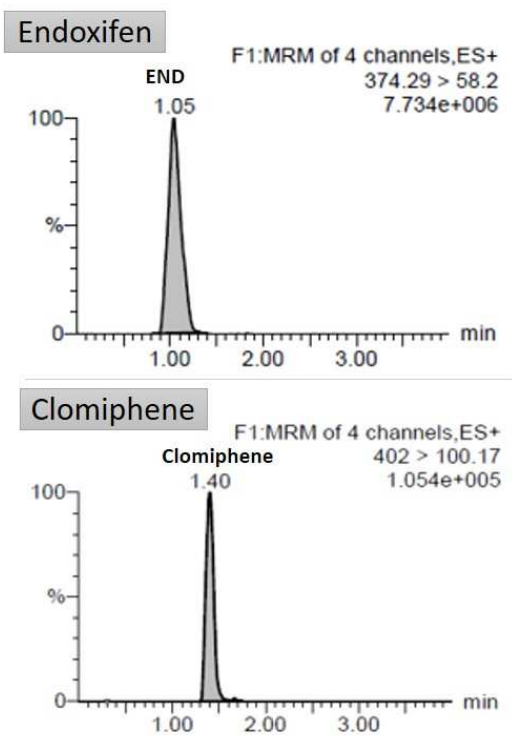

Fig. 5: Chromatogram obtained with $0.1 \%$ formic acid formic acid $0.1 \%$ formic acid in acetonitrile (35:65) at $0.25 \mathrm{ml} / \mathrm{min}$

Table 3: Result of the system suitability test

\begin{tabular}{llll}
\hline Parameter & TAM & END & 4HT \\
\hline \%CV of Area & 1.9 & 4.27 & 4.72 \\
\%CV of Retention time & 1.49 & 0.47 & 0.88 \\
\hline
\end{tabular}

CV: Coefficient Variation. number of experiments (n): 5

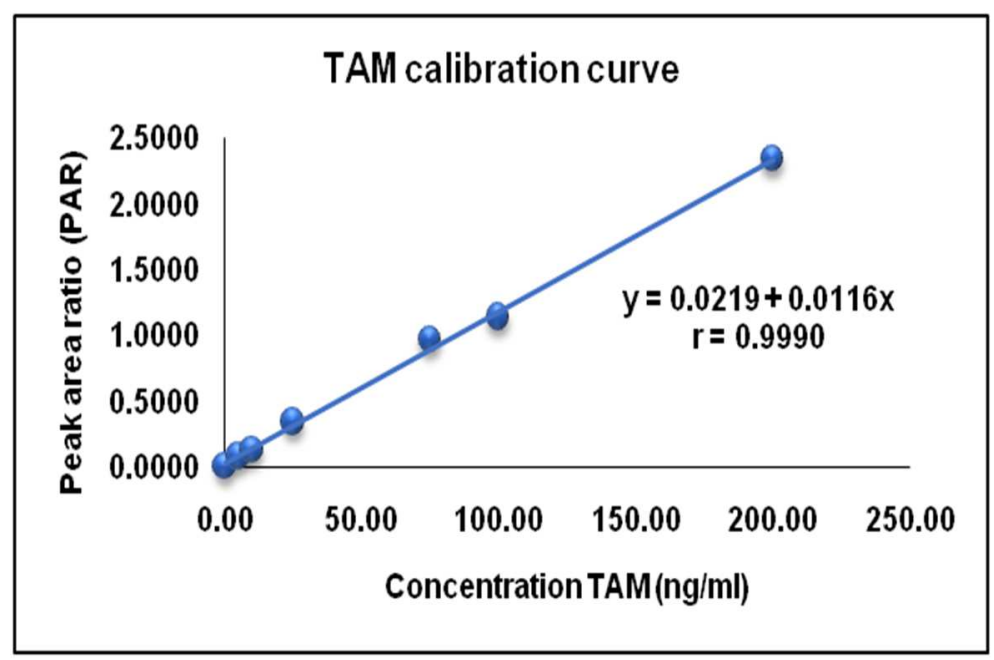

Fig. 6: TAM calibration curve 


\section{Validation assay}

The linearity of the calibration curve was shown for TAM over the range of $5.0-200.0 \mathrm{ng} / \mathrm{ml} ; 1.0-40.0 \mathrm{ng} / \mathrm{ml}$ for END; and $0.5-20.0$ $\mathrm{ng} / \mathrm{ml}$ for $4 \mathrm{HT}$ with a correlation coefficient of 0.99 for those three compounds. The LLOQ for TAM was $5.0 \mathrm{ng} / \mathrm{ml}$; END was $1.0 \mathrm{ng} / \mathrm{ml}$; and $4 \mathrm{HT} 0.5 \mathrm{ng} / \mathrm{ml}$ with a \%CV less than $20 \%$ (fig. 6-8). The resulting calibration curve can be stated linearly and meets the requirements, $\%$ diff not more than $15 \%$ at all concentrations other than LLOQ and no more than $20 \%$ at LLOQ concentrations.

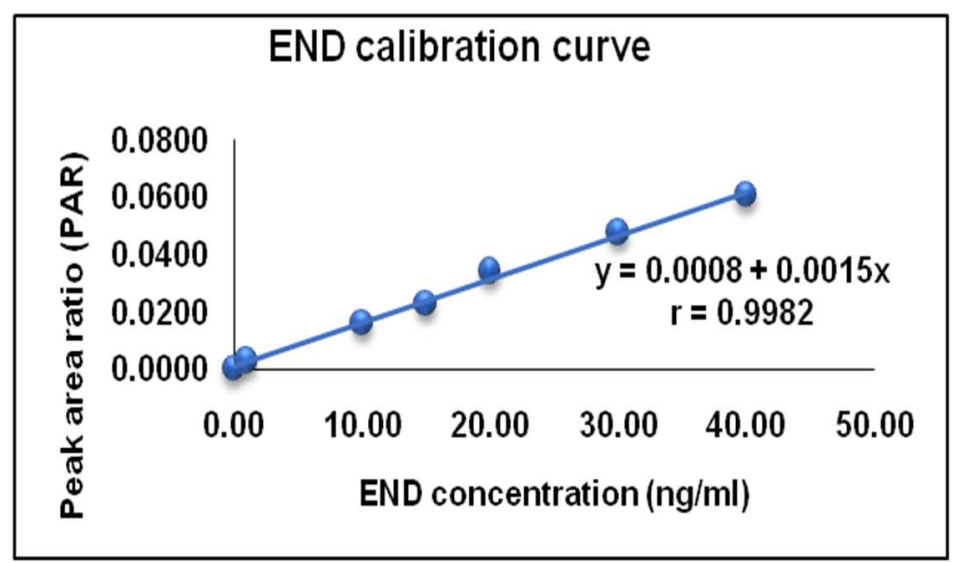

Fig. 7: END calibration curve

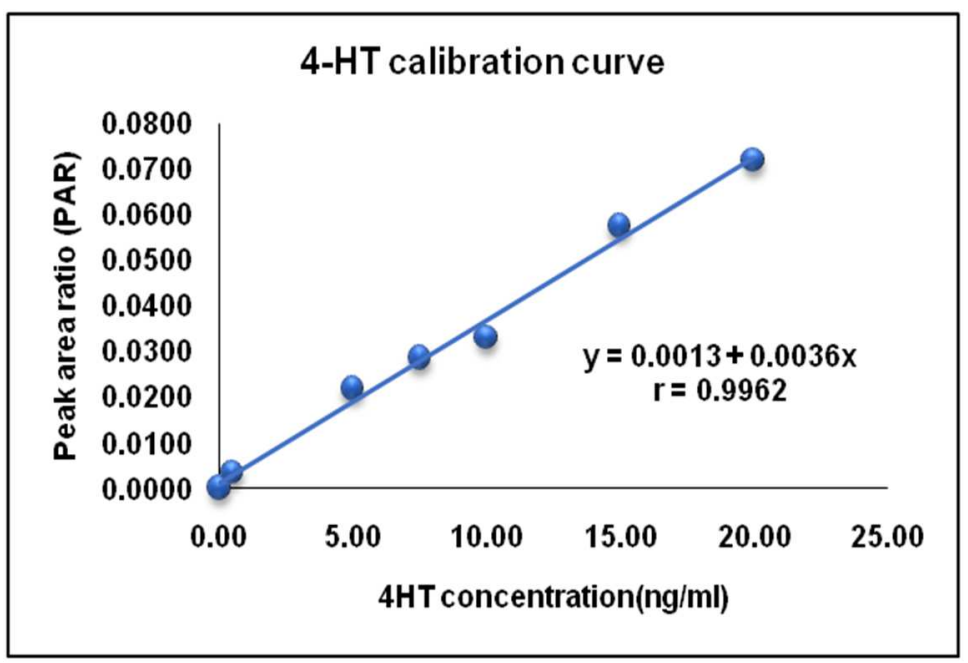

Fig. 8: 4HT calibration curve

The selectivity assay gave the results over the \% interference range of $0.11-9.07 \%$ for TAM; $0.80-13.77 \%$ for END; $2.09-13.73 \%$ for $4 \mathrm{HT}$; and $0.18-0.63 \%$ for CLO. These results indicate that the analytical method developed can selectively analyze TAM, END, 4HT and CLO in a matrix and able to distinguish analytes and internal standards from endogenous components in the matrix or other components in the sample (table 4).

Table 4: Result of selectivity

\begin{tabular}{lll}
\hline Analyte & Conc. $(\mathbf{n g} / \mathbf{m l})$ & \% interference \\
\hline TAM & 5.00 & 9.07 \\
END & 1.00 & 13.77 \\
4HT & 0.50 & 13.73 \\
CLO & 100 & -0.63 \\
\hline
\end{tabular}

Number of experiments (n): 6

Within run and between run Accuracy and precision tests were performed at LLOQ, QCL, QCM, and QCH concentration levels. The accuracy (\%diff value) TAM, END, and $4 \mathrm{HT}$ were less than $20 \%$. The precision (\%CV value) for the within run and between run of TAM, END and 4HT respectively was 4.02-7.44\%; 3.56-9.32\% and 4.65$10.82 \%$ (14).
Recovery was calculated using three replicates at three concentration levels: QCL, QCM, and QCH. The mean recovery (\%recovery value) for TAM, END, and $4 \mathrm{HT}$ was $91.46 \%$; $86.57 \%$; and $78.89 \%$ with $\% \mathrm{CV}$ value less than $15 \%$ for all compounds. The results showed that the method is reliable within the analytical range (table 5). 
Table 5: Result of recovery

\begin{tabular}{lll}
\hline Analyte & Conc. $(\mathbf{n g} / \mathbf{m l})$ & Recovery \\
\hline & & (\% Recovery) \\
\hline TAM & 25.00 & 85.51 \\
& 75.00 & 93.08 \\
END & 150.00 & 95.77 \\
& 5.00 & 84.21 \\
& 15.00 & 90.92 \\
4 HT & 30.00 & 84.58 \\
& 2.50 & 81.22 \\
CLO & 7.50 & 84.38 \\
\end{tabular}

CV: Coefficient variation. number of experiments (n): 3

The carry-over value was calculated after the injection of a high concentration (ULOQ) sample. The carry-over value range of TAM was $0.02-9.22 \%$; $2.61-15.97 \%$ for END; $1.00-17.65 \%$ for $4 \mathrm{HT}$; and $0.01-0.03 \%$ for clomiphene. Those values met the requirement for an analyte area at the LLOQ (no more than 20\%) and 5\% for IS. The results showed no carry-over effect in the blank sample after injecting the highest concentration (ULOQ).
Dilution is one of the steps carried out to obtain standard working solutions and sample preparation. Therefore, it is necessary to ensure that dilution does not affect accuracy and precision. The $\% \mathrm{CV}$ for TAM, END, and $4 \mathrm{HT}$ was less than $15 \%$. The results showed that the dilution of ULOQ sample with a blank matrix did not affect the accuracy and precision of the bioanalysis (table 6).

Table 6: Result of dilution integrity

\begin{tabular}{|c|c|c|c|c|}
\hline Analyte & Conc. (ng/ml) & Result (ng/ml) & Precision (\%CV) & Accuracy (\%diff) \\
\hline \multirow[t]{3}{*}{ TAM } & 300 & $298.84 \pm 10.31$ & 3.45 & -4.39 \\
\hline & 150 & $148.26 \pm 5.67$ & 3.82 & -7.03 \\
\hline & 75 & $71.65 \pm 4.74$ & 6.62 & -10.91 \\
\hline \multirow[t]{3}{*}{ END } & 60 & $59.33 \pm 4.61$ & 7.77 & 10.30 \\
\hline & 30 & $28.57 \pm 2.10$ & 7.35 & -11.20 \\
\hline & 15 & $14.72 \pm 0.72$ & 4.91 & -7.64 \\
\hline \multirow[t]{3}{*}{$4 \mathrm{HT}$} & 30 & $31.19 \pm 2.40$ & 7.70 & 13.15 \\
\hline & 15 & $14.07 \pm 0.69$ & 4.91 & -10.51 \\
\hline & 7.5 & $7.40 \pm 0.79$ & 10.65 & 12.60 \\
\hline
\end{tabular}

CV: Coefficient variation. number of experiments (n): 3

The standard solution stability test showed that TAM, END, 4HT, and CLO standard solutions were stable at room temperature for $24 \mathrm{~h}$ (short term stability) and in the freezer $\left(-20^{\circ} \mathrm{C}\right)$ for $20 \mathrm{~d}$ (long term stability). The stability test for TAM, END, and 4HT in DBS was evaluated under short and long term in storage temperature and autosampler condition prior to analysis. The stability showed that TAM, END, and 4HT were stable at room temperature for $24 \mathrm{~h}$, at 24 $\mathrm{h}$ in the autosampler, and AT room temperature for $20 \mathrm{~d}$. The $\% \mathrm{CV}$ of TAM, END, 4HT, and CLO was less than 15\%. The summary of stability test results are listed in table 7.

Table 7: Stability data

\begin{tabular}{|c|c|c|c|c|c|}
\hline Analyte & Stability & Actual Conc. (ng/ml) & Concentration change (\%) & Precision & Accuracy \\
\hline & & & & $(\% \mathrm{CV})$ & (\%diff) \\
\hline \multirow[t]{6}{*}{ TAM } & Short term & 25.00 & -0.84 & 4.27 & -4.49 \\
\hline & & 150.00 & -0.24 & 4.73 & $-5,59$ \\
\hline & Long Term & 25.00 & 1.28 & 5.40 & 6.93 \\
\hline & & 150.00 & 0.50 & 3.25 & 3.07 \\
\hline & Autosampler & 25.00 & -3.70 & 2.15 & -6.54 \\
\hline & & 150.00 & -4.57 & 2.80 & -4.59 \\
\hline \multirow[t]{6}{*}{ END } & Short term & 5.00 & 3.72 & 5.04 & -5.47 \\
\hline & & 30.00 & -1.11 & 5.93 & -9.01 \\
\hline & Long Term & 5.00 & -2.48 & 7.12 & -12.58 \\
\hline & & 30.00 & 2.70 & 3.02 & 3.67 \\
\hline & Autosampler & 5.00 & -4.38 & 5.43 & -8.41 \\
\hline & & 30.00 & -4.70 & 2.27 & -9.11 \\
\hline \multirow[t]{6}{*}{$4 \mathrm{HT}$} & Short term & 2.50 & -4.76 & 7.29 & -11.88 \\
\hline & & 15.00 & -2.92 & 6.39 & -9.84 \\
\hline & Long Term & 2.50 & -4.36 & 8.55 & -12.79 \\
\hline & & 15.00 & 0.86 & 8.48 & 10.98 \\
\hline & Autosampler & 2.50 & -7.69 & 4.74 & -6.87 \\
\hline & & 15.00 & -5.90 & 5.10 & -9.62 \\
\hline
\end{tabular}

CV: coefficient variation number of experiments (n): 3 


\section{DISCUSSION}

We have developed the UPLC-MS/MS method to analyze TAM and its primary metabolites, END and $4 \mathrm{HT}$ in DBS biosample. During method development, the effect of sample volume, extraction solvent, and sonication time was tested in combination with 4 types of mobile phase and elution mode. The detector response was recorded to observe the effect of each variable. The result showed that we had developed a simple preparation technique that requires only a single step and fast extraction using methanol. The effect of sonication time to detector response was tested from $25 \mathrm{~min}$ to 45 min, as reported by Jager, et al. that 45 min gave the best response [20]. Our result showed that $25 \mathrm{~min}$ has no significance different to 45 min of sonication. Further recovery examination was conducted and proved that $25 \mathrm{~min}$ of sonication gave sufficient recovery and fulfilled precision and accuracy requirements.

The method allows simultaneous analysis of TAM, END, and 4HT with a total analysis time of $4 \mathrm{~min}$ that is obtained by isocratic elution. The low LLOQ values indicates selective and sensitive techniques in order to evaluate the low dose of TAM. We obtained a limit of quantification for END at $1 \mathrm{ng} / \mathrm{ml}$ and for $4 \mathrm{HT}$ at $0.5 \mathrm{ng} / \mathrm{ml}$. The same result also reported by Antunes et al., 2014 but our method used a smaller volume of blood spot. This DBS biosampling method requires an only small amount of blood, $20 \mu \mathrm{l}$, to provide patients convenience.

Extraction recoveries ranged from $71.08 \%$ to $95.77 \%$ were consistent with an acceptable CV within $15 \%$, including IS recovery. Consistent retrieval values at low and high concentration show that throughout this concentration range, the extraction method is acceptable. The DBS samples used in the bioanalytical validation was obtained from venous blood, for practical reasons, while the clinical samples were derivative from capillary blood, the concentration of these two matrices was earlier revealed to vary, largely due to slower distribution equilibrium in the capillaries[21]. To overcome this problem, sampling should be performed in a steady state level in the next clinical application trial, to ensure that the drug has already been distributed.

\section{CONCLUSION}

In conclusion, a rapid, sensitive and easier technique for DBS TAM, END and 4HT quantification with UPLC-MS/MS have been developed and validated. The analytical performance was similar to those outlined in prior technique but with a shorter run time of 6 min, the smallest spot volume of $20 \mu \mathrm{l}$, a single solvent extraction process, and 25 min of sonication. Sensitivity and recovery were also maintained and sufficient enough for quantification of TAM, END, and $4 \mathrm{HT}$ in the patient, even though with low spot volume. This method has successfully fulfilled all validation requirements referring to EMA and FDA guidelines. However, further clinical investigations in the patient should be conducted to fully validated the method and assure its applicability for routine drug monitoring.

\section{ACKNOWLEDGMENT}

The author wishes to recognize the PTUPT grant No. NKB1683/UN2. R3.1/HKP.05.00/2019 from The Ministry of Research, Technology, and Higher Education Indonesia. This donor had no part in designing, collecting and analyzing information, publishing decisions or manuscript preparations.

\section{FUNDING}

Nil

\section{AUTHORS CONTRIBUTIONS}

All the authors have contributed equally.

\section{CONFLICT OF INTERESTS}

None to declare

\section{REFERENCES}

1. Early Breast Cancer Trialists' Collaborative Group (EBCTCG). Relevance of breast cancer hormone receptors and other factors to the efficacy of adjuvant tamoxifen: Patient-level meta-analysis of randomized trials; Lancet 2011. p. 771-84.

2. NGL Jager, SC Linn, JHM Schellens, JH Beijnen. Tailored tamoxifen treatment for breast cancer patients: a perspective. Clin Breast Cancer 2015;15:241-4.

3. MJ Higgins, V Stearns. CYP2D6 polymorphisms and tamoxifen metabolism: clinical relevance. Curr Oncol Rep 2010;12:7-15.

4. AHM de Vries Schultink, W Zwart, SC Linn, JH Beijnen, ADR Huitema. Effects of pharmacogenetics on the pharmacokinetics and pharmacodynamics of tamoxifen. Clin Pharmacokinet 2015;54:797-810.

5. L Madlensky, L Natarajan, S Tchu, M Pu, J Mortimer, SW Flatt, et al. Pierce, tamoxifen metabolite concentration, CYP2D6 genotype and breast cancer outcomes. Clin Pharmacol Ther 2007;86:573-9.

6. P Saladores, T Murdter, D Eccles, B Chowbay, NK Zgheib, S Winter, et al. Brauch, Tamoxifen metabolism predicts drug concentrations and outcome in premenopausal patients with early breast cancer. Pharmacogenomics J 2015;15:84-94.

7. MP Goetz, K Sangkuhl, HJ Guchelaar, M Schwab, M Province, M Whirl Carrillo, et al. Klein, clinical pharmacogenetics implementation consortium (CPIC) guideline for CYP2D6 and tamoxifen therapy. Clin Pharmacol Ther 2018;103:770-7.

8. HI Woo, SK Lee, J Kim, SW Kim, J Yu, SY Bae, et al. Lee, Variations in plasma concentrations of tamoxifen metabolites and the effects of genetic polymorphisms on tamoxifen metabolism in Korean patients with breast cancer. Oncotarget 2017;8:100296-311.

9. SF Teunissen, NGL Jager, H Rosing, AH Schinkel, JHM Schellens, JH Beijnen. Development and validation of a quantitative assay for the determination of tamoxifen and its five main phase I metabolites in human serum using liquid chromatography coupled with tandem mass spectrometry. J Chromatogr B Anal Technol Biomed Life Sci 2011;879:1677-85.

10. J Peris Vicente, E Ochoa Aranda, D Bose, J Esteve Romero. Determination of tamoxifen and its main metabolites in plasma samples from breast cancer patients by micellar liquid chromatography. Talanta 2015;131:535-40.

11. MV Antunes, DD Rosa, T dos, S Viana, H Andreolla, TO Fontanive R. Linden, sensitive HPLC-PDA determination of tamoxifen and its metabolites $\mathrm{N}$-desmethyltamoxifen, 4hydroxytamoxifen and endoxifen in human plasma. J Pharm Biomed Anal 2013;76:13-20.

12. SF Teunissen, NGL Jager, H Rosing, AH Schinkel, JHM Schellens, JH Beijnen. Development and validation of a quantitative assay for the determination of tamoxifen and its five main phase I metabolites in human serum using liquid chromatography coupled with tandem mass spectrometry. J Chromatogr B: Anal Technol Biomed Life Sci 2011;879:1677-85.

13. AJ Wilhelm, JCG den Burger, EL Swart. Therapeutic drug monitoring by dried blood spot: progress to date and future directions. Clin Pharmacokinet 2014;53:961-73.

14. Y Harahap, BP Manggadani, T Ribka, J Sitorus, CA Mulyadi, DJ Purwanto. Clinical application of dried blood spot for monitoring studies of tamoxifen, endoxifen, and 4-hydroxytamoxifen in breast cancer patient using liquid chromatography-tandem mass spectrometry. Int J Appl Pharm 2019;11:59-63.

15. MV Antunes, S Raymundo, V de Oliveira, DE Staudt, G Gossling, GP Peteffi, et al. Linden, Ultra-high performance liquid chromatography tandem mass spectrometric method for the determination of tamoxifen, N-desmethyltamoxifen, 4hydroxytamoxifen and endoxifen in dried blood spotsdevelopment, validation and clinical application during breast c. Talanta 2015;132:775-84.

16. EM Agency. Guideline on bioanalytical method validation. Guideline Bioanalytical Method Validation Table Contents 2012;44:1-23.

17. Food and Drug Administration, Guidance for Industry Bioanalytical Method Validation Guidance for Industry Bioanalytical Method Validation; 2018.

18. M Tre-Hardy, A Capron, MV Antunes, R Linden, P Wallemacq. Fast method for simultaneous quantification of tamoxifen and metabolites in dried blood spots using an entry level LCMS/MS system. Clin Biochem 2016;49:1295-8. 
19. RA Koster, B Greijdanus, DJ Touw, JC Alffenaar. The performance of five different dried blood spot cards for the analysis of six immunosuppressants. Bioanalysis 2015;7:122535.

20. NG Jager, H Rosing, JH Schellens, JH Beijnen. Determination of tamoxifen and endoxifen in dried blood spots using LC-MS/MS and the effect of coated DBS cards on recovery and matrix effects. Bioanalysis 2014;6:2999-3009.

21. BS Mohammed, GA Cameron, L Cameron, GH Hawksworth, P Helms, JS McLay. Can finger-prick sampling replace venous sampling to determine the pharmacokinetic profile of oral paracetamol. Br J Clin Pharmacol 2010;70:52-6. 